\title{
Exploring the range of reported dream lucidity
}

\author{
Remington Mallett ${ }^{1 *}$ \\ Michelle Carr ${ }^{2,3}$ \\ Martin Freegard ${ }^{2}$ \\ Karen Konkoly ${ }^{4}$ \\ Ceri Bradshaw ${ }^{2}$ \\ Michael Schredl ${ }^{5}$
}

${ }^{1}$ Department of Psychology, University of Texas at Austin, USA

${ }^{2}$ Department of Psychology, Swansea University, UK

${ }^{3}$ Sleep \& Neurophysiology Research Laboratory, University of Rochester Medical Center, USA

${ }^{4}$ Department of Psychology, Northwestern University, USA

${ }^{5}$ Central Institute of Mental Health, Medical Faculty Mannheim/Heidelberg University, Mannheim, Germany

*correspondence:

mallett.remy@gmail.com

108 E Dean Keeton St, Austin, TX, 78712

\begin{abstract}
Dream lucidity, or being aware of a dream as it occurs, is not an all-or-none phenomenon. Often, subjects report being some variant of "a little lucid" as opposed to completely or not at all. As recent neuroimaging work begins to elucidate the neural underpinnings of lucid experience, understanding subtle phenomenological variation within lucid dreams is essential. Here, we focus on the variety of lucid experience by asking participants to report their awareness of the dream on a 5-point Likert scale (from not at all to very much). Participants implemented lucid dream induction methods at home for one week and provided detailed reports about their dream experiences each morning. Consistent with previous research, cognitive induction methods led to about half of participants reporting at least one lucid dream and about half of all dreams including some level of lucidity. However, we also show that induction success rate varies significantly depending on the minimum criteria for lucidity. Participants also reported how much they adhered to specific components of each induction method, and the amount of mnemonic rehearsal during a
\end{abstract}


brief early awake period was predictive of lucidity level. Furthermore, lucidity levels were positively correlated with dream control, dream bizarreness, and next-morning positive affect. Lastly, we asked participants open-ended questions about why they chose particular levels of lucidity. We focus a qualitative discussion on responses to those "semilucid" dreams (rated just a little, moderately, or pretty much lucid) to explore why participants rate their dreams as having intermediate levels of awareness. Together, the present study explores the frequency of semi-lucid dreams, what they are, why they might arise, their correlates, and how they impact methodological concerns in lucid dreaming research.

\section{Keywords}

dreaming, lucid, lucid dream induction, consciousness, phenomenology

\section{Author contributions}

Conceived study: RM \& MS

Designed study: RM, MC, KK, CB, \& MS

Collected data: MF

Analyzed data: RM

Drafted manuscript: RM

Revised manuscript: RM, MC, KK, CB, \& MS

Supervised study: CB \& MS

\section{Conflict of interest statement}

The authors declare no potential conflict of interest.

\section{Resource availability statement}

All data and code are available in an OSF repository: https://osf.io/7dwtp/

\section{Word counts}

Abstract - 277

Body - 6906 


\section{Introduction}

In 1913, when he introduced the modern scientific community to the phenomenon of being aware of a dream in real-time: ...the type of dreams which I called "lucid dreams," seems to me the most interesting and worthy of the most careful observation and study... In these dreams the reintegration of the psychic functions is so complete that the sleeper remembers day-life and his own condition, reaches a state of perfect awareness, and is able to direct his attention, and to attempt different acts of free volition. Yet the sleep, as I am able to confidently state, is undisturbed, deep and refreshing. (van Eeden, 1913, p. 446)

This general description of lucid dreaming has been consistent from the earliest objective verifications of lucid dreaming (Hearne, 1978; LaBerge et al., 1981) up to the widelyaccepted modern definition of "becoming aware that one is dreaming while dreaming" (Baird et al., 2019, p. 305). While not explicitly stating so, this definition implies a binary nature of lucidity - either to be or not to be aware of the dream.

However, only pages after introducing the scientific definition that still holds today, van Eeden hints at the continuity of the lucid experience by observing in one instance that "[t]he lucidity had not been very intense, and I had some doubts about my real condition" (van Eeden, 1913, p. 445). In this case, it seems that van Eeden expresses only a partial "level" of lucidity. Despite not having full realization of the dream, he was aware of his condition beyond the typical single-mindedness of non-lucid dreaming (Rechtschaffen, 1978).

Online surveys of lucid dream experiences suggest there is large variation in how individuals pursue, experience, and utilize lucid dreams (Lemyre et al., 2020; Mota-Rolim et al., 2013; Stumbrys et al., 2014). Being fully lucid and aware of the dream state implies that the dreamer can execute predetermined actions within the dream (Erlacher \& Schredl, 2008), yet participants report often not being able to complete their intended actions due to "insufficient clarity" (Stumbrys et al., 2014). Others have reported incidences where lucidity wanes amidst lucid dream task completion, or lucid dream tasks even being completed without specific dream awareness (Worsley, 1984). Moss (1986) proposed a "dream lucidity continuum" ranging from minor dream awareness to fullfledged lucidity and suggested that these lucidity levels are often traversed within a single dream. Similarly, Alan Worsley, one of the most studied and documented modern lucid dreamers, noted "rapid change in the level of lucidity" of his dreams and that "how well [he knows he is] dreaming varies from moment to moment within the same dream" (1988, p. 327). Brooks \& Vogelsong provide a more direct example of how awareness of the 
dream can be present even without a complete grasp of the situation. In a lucid dream report, the dreamer "realized he had left his keys and wallet inside a dream house and made the keys appear in his hand so he could unlock the door to retrieve the wallet" (1999, p. 28). Of course, keys aren't strictly necessary to enter a dream house, which should be even more obvious to the dreamer since they recognized their ability to will the spontaneous presence of keys. Though the dreamer might have other motivation to follow the existing dream layout (e.g., dream stability), such contradictory logic is common even after achieving the analytical feat of dream awareness.

There are many early descriptive accounts of lucid dreaming variation (Gebremedhin, 1987; Gillespie, 1984; Kellog III, 1989; Moss, 1986; Tart, 1985, 1985; Worsley, 1984). Initial attempts to formalize to the lucidity continuum proposed a single "pre-lucid" stage between non-lucid and lucid dreams (Green, 1968). In such pre-lucid dreams, the dreamer questions the nature of the dream, but might conclude (incorrectly) that they are not dreaming. Still others have argued for the necessity of a fourth "incipient/implicit pre-lucid" dream that captures those where the dreamer observes bizarreness without asking the question of whether one is dreaming (Sparrow et al., 2013, 2018). Pre-lucidity was implemented as a level of awareness in subsequent scales (Leslie \& Ogilvie, 1996; Ogilvie et al., 1982; Purcell et al., 1986; Stewart \& Koulack, 1989). Some of these scales offered even more within-lucidity variation, based on length/stability of lucidity (Ogilvie et al., 1982) or the amount of control in the lucid dream (Stewart \& Koulack, 1989).

More modern approaches to measuring lucidity include a variety of questions based on indirect measures of dream awareness, such as levels of insight or selfreflectiveness (Dresler et al., 2014; Kahan \& LaBerge, 2011; Kahan \& Sullivan, 2012; Lee \& Kuiken, 2015; Voss et al., 2013). To-date, the current focus of these scales has not been to quantify the variation within lucid dreams, but rather to strictly contrast lucid versus non-lucid dreams or waking. Voss et al. (2013) used a 6-point Likert scale ranged from Strongly disagree (0) to Strongly agree (5) with probes such as "While dreaming, I often asked myself whether I was dreaming." Factor analysis on these 28 probes revealed that lucid dreams contained more insight, control, thought, memory, dissociation, and positive emotion than non-lucid dreams. Additionally, some lucidity-related factors control, thought, memory, and positive emotion - varied significantly depending on whether the dreams were reported from home or the laboratory. Notably, the scale's range between Strongly disagree and Strongly agree suggests a neutral point (at 2.5),

and although some factors were higher in lucid dreams, they were still below neutral (e.g.,

73 control and dissociation). Therefore, it's unclear if they should be determined as

74 characteristics of lucidity (Voss et al., 2018). Contrasting views have resulted in different 
75 lucid dreaming definitions across studies, for example some including control as a 76 defining characteristic ((Schädlich \& Erlacher, 2012); see also (Horton, 2020)) and others dissociation (Voss et al., 2014). These results highlight the difficulty in measuring lucidity and the characteristics that may or may not encompass dream awareness, particularly through statements that do not directly probe dream awareness.

Only a few questionnaires designed to quantify dream lucidity ask the explicit question about how aware of the dream the participant was. Kahan (1994) asked 82 participants to self-report their lucidity directly on a Likert scale (1-7 with N/A option as 0) 83 by asking them "Were you aware of dreaming while in the dream?" using the Dream 84 Rating Scale. Rather than most responses clustering at 1 (Not at all) or 7 (Very much), $33 \%$ of dreams included a middle level of lucidity (response options 2-6). She concluded that dreams contain a variety of lucidity levels as opposed to a distinct grouping. The Dream Lucidity Questionnaire (DLQ; Stumbrys et al., 2013) is a 12-item questionnaire that asks participants how much they agree with certain statements related to lucid dreaming (e.g., how much control they had over the dream, or how sure they were about being asleep). Responses are made on a 5-point Likert scale ( $0=$ not at all, $1=$ just a little, $2=$ moderately, $3=$ pretty much, $4=$ very much), and the first question is a direct assessment of lucidity on a continuous scale (I was aware that I was dreaming). Dyck et al. (2017) administered the DLQ to investigate the efficacy of a variety of lucidity induction methods and found that while $10 \%$ had dreams with pretty much or very much lucidity, still $33 \%$ of dreams were just a little or moderately lucid. The use of these continuous scales has provided critical insight into the non-binary nature of dream awareness, but the lack of dream reports in the previous studies prevents an understanding of the phenomenology that underlie such ratings.

The goal of the current study was to explore the frequency and phenomenology of semi-lucid dreams, or those that are within the extreme bounds of a Likert lucidity probe. Towards this aim, we took the simplest method of probing a lucidity continuum (how aware of the dream were you, 0-4) and investigated (1) how the full range of the scale was utilized, (2) how measures of induction success were impacted by varying the minimum Likert criterion for lucidity, (3) the relationship between the range of lucidity and other dreaming and waking characteristics, and (4) the phenomenology of semi-lucidity. The notion of lucid dream variability has important implications for how we measure lucidity, which is a crucial topic in this developing field of research (Baird et al., 2019).

\section{Methods}




\section{Participants}

Thirteen undergraduate psychology students from Swansea University participated in exchange for course credit. All participants were female within the age range of 18 and 20 years $(M=19.3, S D=0.7)$, not including one participant with missing demographic data. Participants responded to an advertisement for a study about lucid dreaming. Ethics were approved by Swansea University.

\section{Procedure and lucid dream induction methods}

Participants were emailed an information packet that included general information about lucid dreaming and specific lucid dream induction methods that they were to practice daily for the following week (modeled after Aspy et al., 2017). The email also included a link to a web-based survey that they were asked to complete each morning (see Measures). There is a large variety of existing induction methods (Price \& Cohen, 1988; Stumbrys et al., 2012), yet those that require only behavioral/cognitive training are the easiest to implement in field studies. Therefore, we asked participants to perform a combination of cognitive lucid dream induction methods: both the mnemonic induction of lucid dreams (MILD) and reality checking (RC). MILD - as implemented in the current study - is an induction method that consists of waking up early (after about five hours of sleep), staying awake for a short period of time (generally 5-60 minutes), and returning to bed while mentally rehearsing the intention of becoming lucid during the next dream (LaBerge, 1980). RC is an induction method that is based on brief but regular "reality checks" throughout the day, which are moments where one contemplates the question of whether they are currently dreaming or not (Tholey, 1983). Note that MILD and RC are complementary in that they operate at different timescales. While MILD is a specific practice that occurs during early morning hours and is expected to have more immediate consequences, RC occurs throughout the day and presumably has a more longitudinal impact. Participants were asked to complete both practices to the extent they were comfortable doing so.

\section{Measures}

Participants were asked to, on each morning, complete a web-survey through PsyToolkit (Stoet, 2010, 2017). The survey consisted of a series of questionnaires and open-ended questions. It began with questions regarding their sleep (e.g., bedtime, risetime, sleep quality) and adherence to the induction methods for the previous twentyfour hours. Following an open dream report, participants completed a custom 8-item questionnaire regarding dream characteristics (e.g., bizarreness, sensory vividness, emotionality) and mood upon awakening. Questions were framed, for example, as Please 
note the intensity of bizarreness in the dream. Response options followed a 9-point Likert scale $(1=$ very little, $9=$ a lot, with an additional option $0=$ no recall $)$. The next questionnaire was an extended (19-item) version of the Dream Lucidity Questionnaire (DLQ). The original DLQ (Stumbrys et al., 2013) is a 12-item questionnaire assessing dream awareness and various aspects that often coincide with lucidity (e.g., dream control and access to waking memories). Response options of the DLQ follow a 5-point Likert scale $(0=$ not at all, $1=$ just a little, $2=$ moderately, $3=$ pretty much, $4=$ very much $)$. We extended the original DLQ to include additional probes that assess further aspects of lucidity (as in Dyck et al., 2017, 2018) and dream control, the latter being modeled after the Lucid Dreaming Skills Questionnaire (LUSK; Schredl et al., 2018).

Though we administered the entire extended DLQ, our analyses focus on the first probe (DLQ-1), I was aware that I was dreaming, because this is the most straightforward and direct assessment of lucidity under the current literature definition. The only other DLQ responses used in the current study were those related to control (DLQ probes 4, 6, 8 , and 10), which were averaged together for a single measure of dream control.

The extended DLQ was followed by the Positive and Negative Affect Schedule (PANAS; Watson et al., 1988), which was administered to assess the impact of lucidity on morning affect. The PANAS consists of 20 probes about present moment feeling, equally split across positive and negative affect (e.g., how enthusiastic or scared one feels). PANAS response options follow a 5-point Likert scale $(0=$ not at all, $4=$ very much), and each of the positive and negative affect probes were summed for individual measures of positive and negative morning affect.

Finally, participants completed a series of open-ended questions designed specifically to probe why a lucidity level (i.e., DLQ-1 response) was selected. Participants were asked (1) Why did you rate your awareness at the value you did (2) What kind of experience(s) gave you an impression of your selected level of awareness, and (3) What prevented you from attributing full awareness to your dream. We found the first question to ultimately be the most useful for interpreting why participants chose different levels of lucidity, and thus focused our results on responses to only that question.

\section{Analyses}

Lucidity induction. First, we simply counted the frequency of each level of lucidity (DLQ-1 response) reported by participants for each night of their diary. Second, we combined all participants to get frequency counts for each lucidity level aggregated across all nights in the sample. Third, we calculated induction success rates at the group level according to different lucid dream cutoffs. There are many ways to measure lucidity, as well as many ways to measure lucid dream induction success. To highlight this, we report 
186 lucid dream frequency (i.e., induction success) in three different ways. Each participant's 187 lucid dreaming frequency was calculated as the fraction of nights that include a lucid 188 dream according to each cutoff point (from a minimal cutoff of just a little lucidity up to a 189 strict cutoff of very much). We averaged this lucid dreaming frequency across all 190 participants to calculate induction success rate of the sample at each cutoff point. We 191 repeated this process first using all diary nights, then using only those nights with dream 192 recall. To compare the effects of varying the lucidity cutoff and changing the inclusion of 193 nights without recall, we ran a 2-way repeated measures ANOVA using the Python 194 package Pinqouin (Vallat, 2018), with one factor as 'nights included' (all vs. only those 195 with dream recall) and the other factor as 'lucidity cutoff' (just a little, moderately, pretty much, very much). Lastly, we also report a binarized measure of lucid dream frequency that represents the fraction of participants that became lucid at least one night, again at each lucidity cutoff.

To investigate how adherence to the prescribed induction methods influenced lucidity level, we ran a mixed effects ordinal regression model using the $\mathrm{R}$ package ordinal (Christensen, 2019) with MILD rehearsal length, MILD awake time, and the number of reality checks performed the previous day as predictors of DLQ-1 response. Thus, each model predictor was evaluated for its independent contribution to variation in lucidity level. This analysis was first run including all nights regardless of whether a dream was recalled. We also report the same analysis after dropping nights without recall.

Semi-lucid interrogation. A main goal of the current study was to qualitatively assess the reasons for denoting a dream as semi-lucid. We interpreted responses 1-3 (just a little, moderately, and pretty much) to the DLQ-1 as being semi-lucid, or semiaware of the dream as it was occurring. To interrogate participants' reason for a semilucid response selection, we focused on the open-ended question: Why did you rate your awareness the way you did? Answers were grouped according to DLQ-1 response and evaluated qualitatively.

Correlates of lucidity. With a continuous measure of lucidity, we were able to investigate its relationship with other dream characteristics and morning affect. All correlations were run using Kendall's tau $(\tau)$ correlation measure, preferred for ordinal data (Somers, 1962). Because each participant reported a unique amount of dreams, we ran a resampling method where a random night with recall was sampled from each participant and then a single $\tau$ value was computed. This process was repeated 1000 times, and then all $\tau$ values were Fisher $z$ scored. For two-tailed significance tests, the smaller of the two proportions of $z$ scored values above and below zero was doubled. 


\section{Results}

Though all participants were asked to report their dream each morning for one 227 week, participants contributed varying amounts of morning reports (Figure 1A). When 228 aggregating across all participants, each of the four nonzero lucidity options appears to

A)
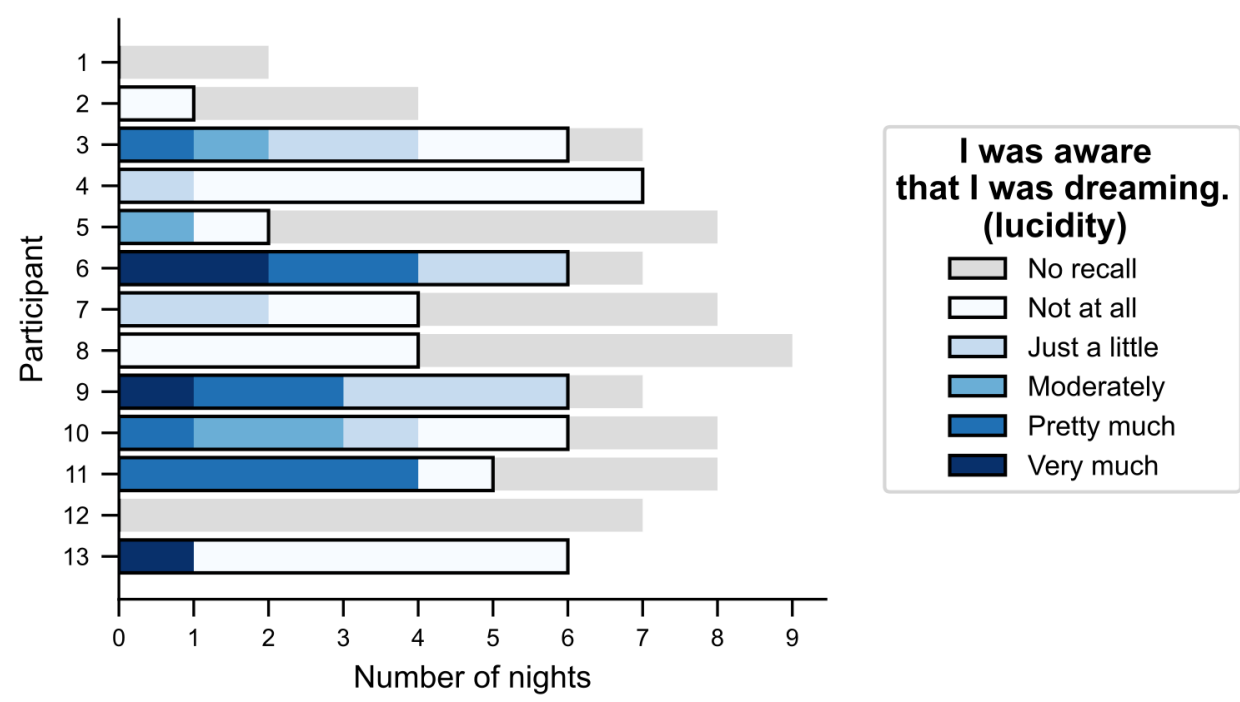

B)

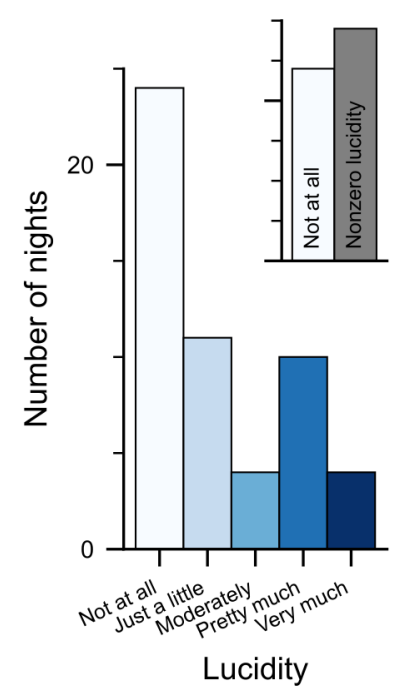

C)

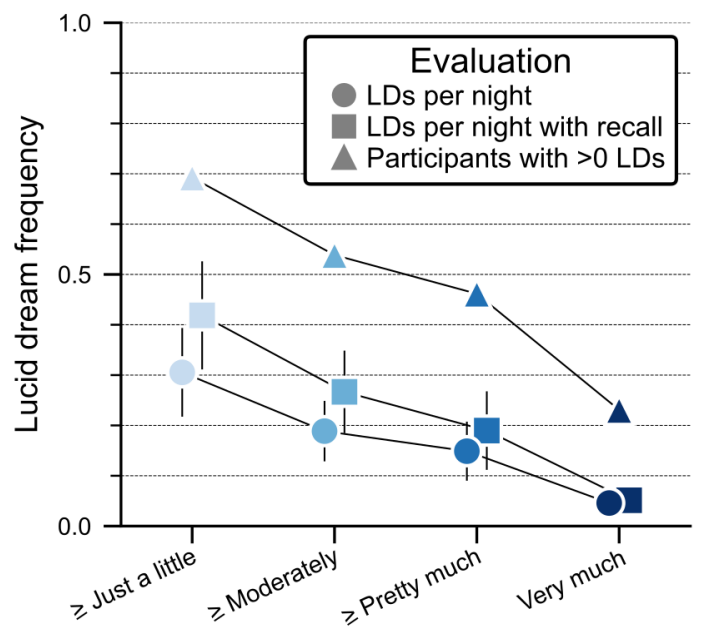

Lucidity cutoff

Figure 1. Lucidity induction. A) Display of individual differences of DLQ-1 range utilization. B) Roughly half of nights with dream recall included nonzero lucidity, and all nonzero scale options were utilized similarly. Upper right inset aggregates all the nonzero lucidity response options together, shown on the same scale. C) Lucidity induction success varies across a variety of measurement approaches. Evaluations include the frequency of lucid dreams across all night (circles), across only nights with recall (squares), and the frequency of participants that had 1 or more lucid dreams (triangles). Error bars represent SEM. 
229 be chosen roughly equally (Figure 1B). The frequency of dreams reported as having 230 nonzero lucidity (i.e., at least just a little) appear similar to the aggregate frequency of 231 those with no lucidity (Figure 1B, inner panel). Across a variety of cutoffs used to 232 measure lucid dream frequency, induction success varied from $5 \%$ to $69 \%$ (Figure 1C).

233 Unsurprisingly, reporting lucid dream frequency as a function of all nights rather than only 234 nights with dream recall resulted in lower frequencies $(F=8.2, p=.014)$, and 235 implementing a more stringent criterion for a lucid dream resulted in lower frequencies $(F$ $236=10.0, p<.001)$. There was also an interaction, such that a more stringent lucidity 237 criterion was less impacted by the choice of restricting to nights with dream recall $(F=$ $2385.0, p=.006)$. It's clear visually in Figure $1 \mathrm{C}$ that the rate of participants who became 239 lucid at least once according to each cutoff is higher than the induction rates across all 240 nights in a sample. These results suggest that how lucid dream frequency is measured has significant impacts on how induction method results are reported and interpreted.

MILD rehearsal length was a significant predictor of lucidity level (odds ratio $=1.2$, odds ratio $\mathrm{Cl}=[1.0,1.4], p=.027$; Figure 2), but this was not the case for MILD awake time $(p=.133)$ nor the number of reality checks performed $(p=.713)$. The effect of MILD rehearsal length was consistent when we only included nights with dream recall $(p=$ .062). These results suggest that the mental exercises involved in MILD have a strong

247 influence on lucidity level, even after controlling for the length of the MILD waking period 248 and recent reality check frequency.

A)

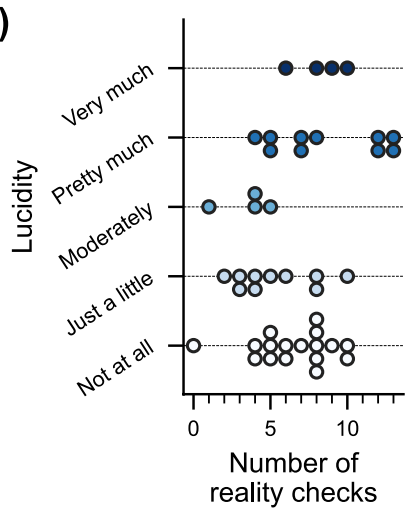

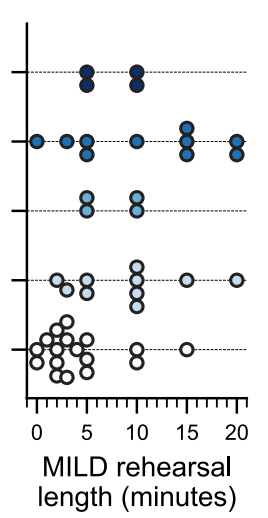

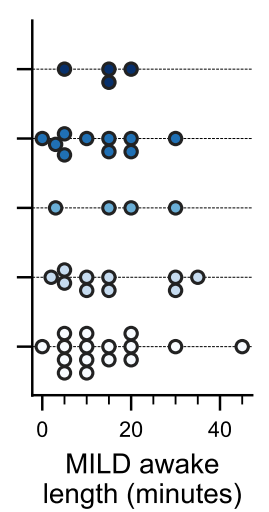

B)

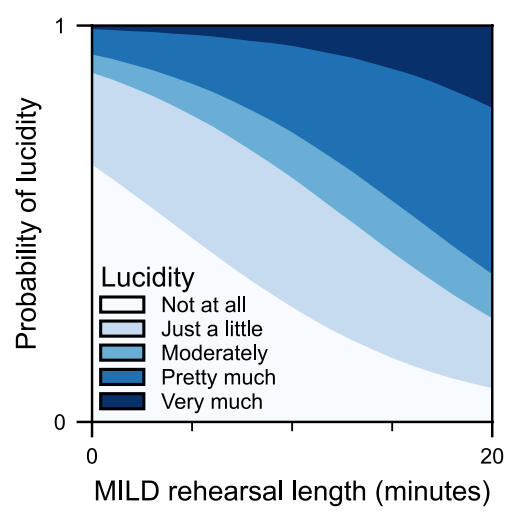

Figure 2. Induction method adherence and lucidity level. A) Only MILD rehearsal length was significantly predictive of attained lucidity level. Note that slight variation around each lucidity level ( $y-$ axis gridlines) is to show all data points and does not represent variation in values, and participants might contribute multiple datapoints to each plot. B) The significant effect of MILD rehearsal length plotted differently, as continuous model predictions after being fit with empirical data. 
253 qualitative assessment of the open question Why did you rate your awareness the way 254 you did? supports this notion as well (Figure 3). Participants tended to defend their selection of just a little lucidity with comments that suggested they were not lucid by the strict definition (e.g., "I only knew the situation was odd"; "I had no idea I was asleep"). The selection of moderately lucid seemed to consist of dreams that had tendencies 258 towards observing non-realness but without explicit dream awareness, perhaps in line with notions of implicit pre-lucidity (e.g., "The dream at moments felt real"; "...the things occurring in my dream were too bizarre to be real life"). Dreams reported as pretty much lucid start to include responses that appear to fit the modern criterion for lucidity (e.g., "Because I realized I was dreaming"), but with deficits in features of lucidity such as dream length (e.g., "...it took me a while to realize I was asleep"), stability (e.g., "I was mostly aware that I was dreaming but at times things felt more real"), or control (e.g., "... I was able to partially control it").

In summary, when asked about their motivation for selecting semi-lucid levels, lowend semi-lucid dreams (i.e., just a little) tended to not include any levels of "awareness" but rather just skepticism (similar to the existing definition of pre-lucid or implicit pre-lucid dreams). In contrast, high-end semi-lucid dreams (i.e., pretty much) tended to include awareness but not control. These results are important given the current lack of 271 agreement over methods of measuring lucidity (Baird et al., 2019). With a formal definition 272 of just awareness and not specifically control, it seems our low-end semi-lucid dreams do 273 not meet this definition, but our high-end semi-lucid dreams do. These results might be

I was aware that I was dreaming.

Not at all

Why did you rate your awareness the way you did?

I believed it was reality whan I was dreaming and had no doubt that it wasn't.

\section{Moderately}

The dream at moments felt real.

Because the things occurring in my dream were too bizarre to be real life.

I was aware that what was happening in the dream made no sense...

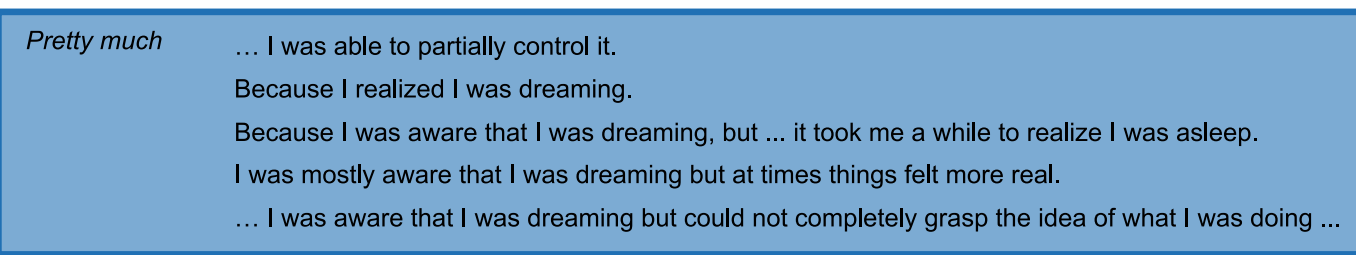

Very much

I was fully aware I was dreaming

Figure 3. Semi-lucidity interrogation. Representative defenses of why participants picked each DLQ-1 response (i.e., lucidity level). 
274 interpreted as lucidity levels binning into a "low" and "high" lucidity, yet this brief 275 assessment seems consistent with the use of a 5-point Likert scale to assess lucidity, as 276 each response level reveals a unique pattern of response profiles.

Participants reported dream characteristics and morning affect upon awakening, all of which were tested for correlations with reported lucidity (Figure 4A). Lucidity level was correlated with dream control (mean $z=.89, p<.001$ ) and dream bizarreness (mean $z=.61, p=.002$ ). There was a positive trending relationship between lucidity and dream

283 sensory vividness (mean $z=.37, p=.084$ ), as well as positive dream body sensations 284 (mean $z=.37, p=.080$ ). We were also interested in how dream lucidity was related to 285 affect upon awakening. We found that lucidity level was positively correlated with positive 286 morning affect (mean $z=.38, p=.032$ ), but showed no relationship with negative morning 287 affect (mean $z=.06, p=.754$ ).

A)

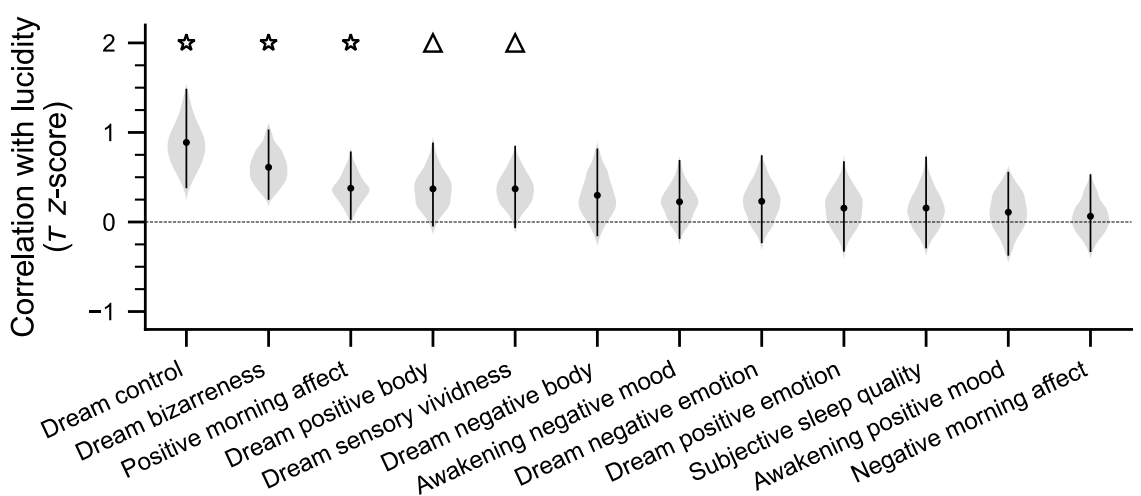

B)

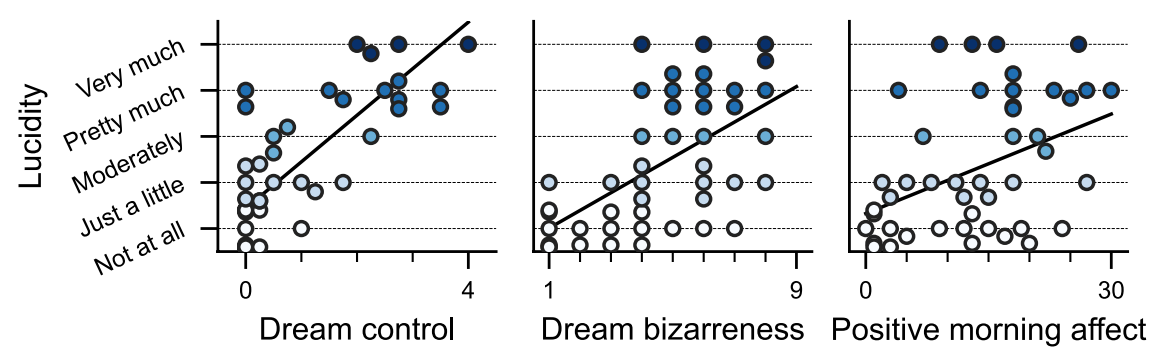

Figure 4. Lucidity level correlates. A) Dream control and dream bizarreness were the strongest dream characteristic predictors of lucidity level. Positive, but not negative, morning affect increased along with lucidity. Slope lines are averaged across all resampled correlations. Stars indicate $p<.05$, triangles indicate $p<.10$. B) The strongest relationships with lucidity plotted with full dataset. Note that slight variation around each lucidity level (y-axis gridlines) is to show all data points and does not represent variation in values, and participants might contribute multiple datapoints to each plot. 
Now that there is little debate about the existence of lucid dreaming as a phenomenon (Baird et al., 2019), the field's focus has moved from the goal of verifying lucid dreams (LaBerge et al., 1981) to their neural correlates (Dresler et al., 2012; Voss et al., 2009), how to induce them (Blanchette-Carrière et al., 2020; Carr et al., 2020; LaBerge et al., 2018; Voss et al., 2014), what sleep stages they occur in (Stumbrys \& Erlacher, 2012), and how they can be used for therapeutic purposes (de Macêdo et al., 2019; Ellis et al., 2020; Spoormaker \& Bout, 2006). With the current study, we propose that an additional line of investigation should be into the non-binary expression of dream awareness within lucid dreams (see also Mota-Rolim et al., 2010; Noreika et al., 2010; Stumbrys \& Erlacher, 2014). Focused analyses examining the continuous nature of being aware of a dream have rarely been explored, yet might provide more sensitive insight into what induces lucidity and how lucidity impacts waking life. By focusing on a 5-point Likert scale of specific awareness of the dream, we were able to observe a variety of novel features of the proposed lucidity continuum (Moss, 1986).

\section{Semi-lucid dreams}

All nonzero lucidity levels (anything above not at all aware of the dream) were utilized equally across our sample. This finding suggests that lucidity follows a natural continuum. Further, when we interrogated participants' reason for selecting semi-lucidity (just a little, moderately, or pretty much), responses were consistent with this notion. Participants reported just a little lucid dreams as most frequently containing only skepticism about the dream or observations of bizarreness, consistent with the previous categorization of pre-lucid dreams (Green, 1968), or more specifically, implicit pre-lucid dreams (Sparrow et al., 2013, 2018). Some such dreams were by all definitive criterion non-lucid, as they were not aware of the dream. Moderately lucid dreams were similarly full of skepticism, albeit to a stronger degree. It was not until the pretty much lucid dreams that participants began to report explicit awareness of the dream. Why then were these dreams not reported as very much lucid? Most responses included certain limitations of lucidity, such as a lack of control, or a fleeting lucidity that appeared only at the beginning or end of the dream. The current definition of lucid dreaming does not include dream control (Baird et al., 2019; Horton, 2020), although dream control is typically higher in lucid than non-lucid dreams (LaBerge et al., 2018; Voss et al., 2013). Also note that van Eeden's (1913) original description of lucid dreams included dream control elements. Our results warrant future discussion about how control fits into the strict definition of lucid dreaming. 
Viewing only the Likert responses to I was aware that I was dreaming suggests that lucidity falls along a true continuum, and that further variation in response options might capture more of it. While our results suggest a lucidity continuum, they also do not refute a lucidity spectrum containing clear boundaries or quantized sections on a subscale. It is also possible to interpret the open-ended responses as evidence for a binary nature of lucidity. That is, under a strict definition of being fully aware of the dream as it is occurring, our results suggest that only pretty much and very much lucid dreams are truly lucid dreams, while just a little and moderately lucid dreams might actually be pre- or non-lucid. The criterion of being fully lucid is not included in the current literature definition of a lucid dream, and so future consideration of this is important. Others have argued that a good criterion of gauging lucidity is to simply ask the participant if they were lucid, offering just yes and no as response options (Baird et al., 2019). While on the surface this seems the most straight-forward way of determining lucidity, it is possible that forcing participants into a binary categorization of something that might be non-binary could result in false positives and misses.

Another approach to lucidity variation, not exclusive to the above-mentioned, is that even within fully lucid dreams lies a variety of cognitive profiles (Barrett, 1992; LaBerge \& DeGracia, 2000; Lee, 2018; Sparrow, 2019). Interesting new studies have investigated the degree to which self-reflectiveness relates to within-dream memory (e.g., During my dream, I remembered what happened earlier in the dream; Lee, 2017, 2018). Future work might investigate whether such high-level cognitive processes such as access to long-term memory vary as a function of reported lucidity. Given the unique neural profile of lucid dreaming (Baird et al., 2019), teasing apart the specific cognitive components of lucid dreaming can make broader contributions to how the waking brain effectively implements higher-order cognition.

Our interrogation of semi-lucid dreams also suggests that there are individual differences in what one qualifies as lucidity. How someone chooses to report their lucidity on a continuous scale is likely to be dependent on their previous lucid dreaming experience. If a participant's first experience with lucidity is momentary and without dream control, they might rate it as very much lucid. But then after a subsequent lucid dream that includes dream control, the same participant might reevaluate their use of the lucidity response options and drop the same experience to pretty much lucid. A longitudinal dataset collected with a methodology similar to that presented here might be able to address how the use of the reported lucidity range changes as a function of experience with lucid dreams. In a similar vein, it seems clear that lucid dreaming can be learned (LaBerge, 1980; Price \& Cohen, 1988; Stumbrys et al., 2012), yet whether it is a proper skill (i.e., retained without consistent practice) or an ability (i.e., lost without consistent 
364 practice) is still undetermined (Schredl et al., 2018). Collecting continuous lucidity reports 365 before, during, and after lucid dream training might help to answer this and related 366 questions.

\section{Methodological decisions in reporting induction success}

Entangled with the issue of measuring lucidity is the question of how to measure lucid dream induction success (Stumbrys \& Erlacher, 2014). The immense promise of lucid dreaming is limited by the capacity to experimentally induce lucidity (Appel et al., 2018), and thus a leading goal of the field is to develop reliable lucid dream induction methods. The method of quantifying induction success rate is often inconsistent across experiments, and might be one of the contributing factors to literature discrepancies (Stumbrys et al., 2012). Induction success is often reported as a proportion of lucid dreams, but this might be a proportion of all attempts, a proportion of all reported dreams (i.e., excluding attempts without dream recall), or a proportion of participants that become lucid (i.e., not accounting for multiple attempts within each participant). Our results suggest that the success rate varies significantly depending on this selection. Unsurprisingly, our results also show that the success rate is further dependent on the operationally defined lucid dream; success rate decreases as the criterion for what constitutes a lucid dream becomes increasingly stringent along the range of reported lucidity. Importantly, these success rates differ dramatically and have a significant impact on the interpretation of a given induction method.

While we show that the choice of measuring induction success measure matters, it is difficult to advise one over another. The optimal metric to use for success rate should differ across study motivations. On the one hand a therapeutic approach might be more concerned with only how many participants become lucid, since the primary motivation is to increase lucidity at some point across repeated attempts. On the other hand, laboratory investigations, due to time and effort, might be more concerned with how effective an induction method is at inducing lucid dreams on a single attempt. Similarly, despite the common practice of removing nights without dream recall (since it is possible a lucid dream was forgotten), knowing induction success across all attempts would be critical to

394 how effective an induction method is. Thus, a best-practices approach might be to include all success rates to aid in cross-study comparisons.

Another possible reason for discrepancies in induction success across studies and induction methods is that they might induce different profiles of lucidity (LaBerge \& 398 DeGracia, 2000). As we highlight here, lucidity lies along a continuum, and different 399 induction methods might induce different but predictable levels of lucidity. Despite the 400 combination of MILD and reality checking inducing varying levels of lucidity in the current 
401 study, it's possible that a given induction method might be effective in so far as it induces 402 strictly low or strictly high levels of lucidity. Often the goal of inducing lucid dreams is to 403 induce fully lucid dreams - even dream control specifically - for experimental control over 404 dream actions or for nightmare sufferers to overcome negative dream content. Thus, it 405 will be crucial for future research to clarify the level of lucidity induced with a given 406 induction method.

Adherence to lucidity induction protocols

The mnemonic induction of lucid dreams method (MILD), as implemented in the current study, involves waking up in the middle of the night and staying awake for a brief period of time while performing a mental rehearsal task (LaBerge, 1980). The mental rehearsal task to be performed during this brief awake period involves setting an intention to remember to become aware during the next dream and imagining the moment of lucidity. A related lucid dream induction method is known as wake-back-to-bed (WBTB), which entails waking up for a period of time during the night and then returning to sleep (Stumbrys et al., 2012; Stumbrys \& Erlacher, 2014). Because WBTB is primarily a behavioral technique and does not specify what action is performed while awake (e.g., (Appel et al., 2020; Erlacher \& Stumbrys, 2020)), it is often used in conjunction with cognitive techniques such as MILD. To simplify instructions for our participants, we used the term "MILD" in its originally proposed implementation (LaBerge, 1980), a combination of WBTB's behavioral aspect and MILD's cognitive aspect. While both methods are effective at inducing lucidity, the mechanism behind their efficacy is unclear. WBTB is presumed to aid in "catching" a REM cycle, where lucid dreams are more likely to occur (LaBerge, 1988; LaBerge et al., 1981), a hypothesis that has recently received preliminary support (Gott et al., 2020). Another contributor to WBTB's efficacy, not mutually exclusive from such REM re-entry, is the cognitive activity of the brief awake period (Erlacher \& Stumbrys, 2020). MILD was originally devised based on the notion of prospective memory, or setting an intention during waking to remember one is dreaming during the next dream (LaBerge, 1980; Tholey, 1983). Our data suggest that the mental rehearsal component of MILD serves as a primary catalyst for inducing lucidity. Aspy et al. (2017) found contrasting results in that longer MILD practice led to decreased chance of achieving lucidity, although they note that this effect was likely a result of MILD practice impacting sleep habits. It is possible that our approach of relating induction method adherence to the degree of lucidity, rather than strictly lucid or not, can help to uniquely reveal the efficacy of certain lucid dream induction methods. 
438 longer intervals, 30-60 minutes of awake time during the morning is optimal for inducing 439 lucidity compared to shorter intervals of approximately 10 minutes (LaBerge et al., 1994), 440 but a comparison within shorter intervals showed $\sim 5$ minutes awake time to be more 441 effective than $\sim 10$ minutes (Aspy et al., 2017). We found no effect of awake time on 442 lucidity level, leaving this still an open question.

443 Another popular method of inducing lucidity is reality checks (Stumbrys et al., 444 2012; Tholey, 1983). The likely reason for this method's broad popularity and appeal is 445 that it doesn't incur any modification to typical sleep habits, which is a concern for other 446 induction methods (Soffer-Dudek, 2020; Vallat \& Ruby, 2019). The proposal behind the 447 efficacy of reality checks is rooted in the continuity hypothesis of dreams, which states 448 that we dream about themes from our waking life (Schredl \& Hofmann, 2003), even if not 449 specific episodic replay (Fosse et al., 2003; Malinowski \& Horton, 2014; Mallett, 2020). If 450 one asks themselves if they are dreaming throughout the day, then the theory of reality 451 checks proposes that they will also ask themselves while they are dreaming, and ideally 452 come to the correct conclusion that they are amidst a dream. Notably, it is possible to ask 453 yourself if you are dreaming during a dream and incorrectly resolve to no. The efficacy of 454 reality checks alone as an induction method is contentious (Stumbrys et al., 2012) and 455 has recently shown no singular effect at increasing lucidity (Aspy et al., 2017; Dyck et al., 456 2017), however seems to work when used in combination with other induction methods 457 (Aspy et al., 2017; Stumbrys et al., 2012). In the current study, we found no relationship 458 between the amount of reality checks performed in a single day and the amount of lucidity 459 in the subsequent night, which is consistent with recent work (Aspy et al., 2017). However, waking memories are frequently incorporated into dream content after a few days rather than on the subsequent night (Blagrove et al., 2011; van Rijn et al., 2015). Future work might account for this "dream-lag effect" with the specific prediction that the number of reality checks performed a few days before might be more predictive of dream lucidity.

\section{Lucidity and bizarreness}

The content of lucid and non-lucid dreams has been suggested to be more similar than different (Gackenbach, 1988; Kahan \& LaBerge, 2011). However, the relationship between lucidity and bizarreness is still unclear. Lucid and nonlucid dreams might be similar in bizarreness (Voss et al., 2013), yet when rated by external judges non-lucid dreams show higher bizarreness (Yu \& Shen, 2020). Our study suggests that increased dream bizarreness is related to increased dream lucidity. Another recent study found lucid dreams to be higher in bizarreness than non-lucid dreams (LaBerge et al., 2018),

473 although these results are conflated with the ingestion of galantamine, which might have influenced dream bizarreness independently of lucidity (although see Sparrow et al., 
475 2016). There is an intuitive notion that naturally occurring lucidity occurs as a result of a 476 bizarre dream event (sparking the dreamer's realization "how strange, I must be 477 dreaming"), but this is inconsistent with the high frequency of bizarre events that do not provoke lucidity. As with our finding of a positive relationship between lucidity and sensory vividness, we are unable to determine if bizarreness induced lucidity. Among other possibilities, perhaps increased lucidity allowed for a more direct/reflective evaluation of dream content, lucidity made dreams more bizarre, or a third variable (e.g., cortical arousal) induced both lucidity and bizarreness. A further consideration is that different levels of lucidity might be initiated by different dream characteristics.

Positive impact of lucidity

A promising benefit of lucid dreaming is its potential for nightmare therapy (Abramovitch, 1995; Aurora et al., 2010; de Macêdo et al., 2019; Garfield et al., 1988; Gieselmann et al., 2019; Holzinger et al., 2015; Mota-Rolim \& Araujo, 2013; Payne, 2014; Taitz, 2014; Zadra \& Pihl, 1997). The initially proposed idea behind lucid dreaming therapy is that lucid dreamers have control over their dream content, and thus can actively change the narrative of a dysphoric dream. However, recent studies have shown that lucid dreaming training sometimes improves nightmare symptomology despite a lack of induced lucidity (Spoormaker et al., 2003; Spoormaker \& Bout, 2006), or might reduce only nightmare-related symptoms (Holzinger et al., 2020). Our results suggest the possibility that in such situations, lucid dreaming training might induce low levels of lucidity potentially undetectable using a binary lucidity outcome measure. Our semi-lucid interrogations are in line with others suggesting that not all lucid dreams include dream control (Mota-Rolim et al., 2013; Schredl et al., 2018; Stumbrys et al., 2014). It is also possible to have control over dream actions but not the environmental surroundings (Schädlich et al., 2017). But without inducing dream control, how could lucid dreaming therapy be effective? One possibility is that the moment of lucidity brings with it a sense of relief, even if the content can't be changed. While this "just a dream" realization typically occurs when one awakens fully from a nightmare, there might be a particular impact of having this realization within the same environment of the nightmare event. For example, the emotional response to the ongoing nightmare might be different if the dreamer is aware of its non-reality. Another way to assess the clinical benefit of lucid dreaming is to quantify affect in the morning following a lucid dream (Konkoly \& Burke, 2019; Stocks et al., 2020). Our results suggest that increased lucidity leads to increased morning affect, which might be another potential clinical benefit to lucid dreaming beyond the strict control

510 of nightmares. Recent work suggests that characteristics of the dream state carry over 511 into wakefulness (Lee \& Kuiken, 2015; Sikka et al., 2018), and lucid dreams contain more 
512 positive emotions than non-lucid dreams (Voss et al., 2013). Thus, the positivity of lucid

513 dreams carrying over into the waking state might offer a reason for why lucid dreams 514 without control could benefit nightmare sufferers (Stocks et al., 2020). We found a clear 515 positive relationship between lucidity and dream control, and so our results are unable to 516 determine whether dream control was responsible for these positive waking impacts. 517 Notably, lucid dreaming therapy has recently been scrutinized for its potential negative 518 impact due to occasional sleep interruptions and/or reality-fantasy questioning (Soffer519 Dudek, 2020; Vallat \& Ruby, 2019). Our data shows no relationship between lucidity and 520 negative affect or subjective sleep quality (as in (Aspy, 2020; Ribeiro et al., 2020; 521 Schadow et al., 2018; Schredl et al., 2020; Stocks et al., 2020)), however we did not 522 implement measures of psychosis, which will be important for future lucid dream induction 523 studies.

While bodily sensations are under-appreciated within the discussion and 525 description of lucid (Garrett, 2017; Kühle, 2015) and non-lucid (Windt, 2010) dreams, the same logic of carry-over effects might apply to the positive body sensations that increased with lucidity levels in the current study. Lucid dreamed actions share the neural substrate of waking actions (Dresler et al., 2011; Erlacher \& Schredl, 2008) and might have the same carry-over effects from dream experience into waking (Stumbrys et al., 2016).

The continuity of consciousness

Not only dream awareness, but also waking self-reflection fluctuates amongst a continuum (Fazekas \& Overgaard, 2016, 2018; Kahan \& LaBerge, 2011; Kahan \& Sullivan, 2012; Smallwood \& Schooler, 2015). The unique state of non-lucid dreaming and its variants (Nielsen, 2004, 2017; Windt et al., 2016) - can offer unique insight into the study of consciousness more broadly (Fazekas \& Nemeth, 2018; Hunt, 1986; Revonsuo \& Valli, 2010; Windt et al., 2016; Windt \& Noreika, 2011). Lucid dreaming is often referred to as a stop along a continuous range (Fazekas \& Nemeth, 2018; Hobson et al., 2000), and our results suggest further that studying variation within lucid dreams can offer further insight into studies of consciousness (Baird et al., 2019; Hobson, 2009). Future work into the neurophysiology of lucidity variation might aid in understanding the

542 (waking) neural basis of cognitive components that are specific to lucid dream sub-types

543 (Mota-Rolim et al., 2010). The characterization of the continuous nature of self-reflective 544 awareness in waking has important implications for the diagnoses and treatment of 545 clinical disorders of consciousness (Fernández-Espejo \& Owen, 2013). 
548 In summary, the current study was a largely exploratory investigation into the 549 varieties of dream awareness. By focusing our analyses on a Likert-scale probe aimed 550 directly at dream lucidity, we explored specific relationships between reported lucidity 551 level and induction adherence, dream characteristics, morning affect, and 552 phenomenology. Our goal was to contribute to the current methodological discussion of 553 how lucidity should properly be measured and described in future research. In doing so, 554 we showed that participants report dreams as consisting of a range of lucidity, but how 555 dream researchers interpret the use of this range is still open for discussion. 


\section{REFERENCES}

Abramovitch, H. (1995). The nightmare of returning home: A case of acute onset nightmare disorder treated by lucid dreaming. Israel Journal of Psychiatry and Related Sciences, 32(2), 140-145.

Appel, K., Füllhase, S., Kern, S., Kleinschmidt, A., Laukemper, A., Lüth, K., Steinmetz, L., \& Vogelsang, L. (2020). Inducing signal-verified lucid dreams in $40 \%$ of untrained novice lucid dreamers within two nights in a sleep laboratory setting. Consciousness and Cognition, 83, 102960. https://doi.org/10.1016/j.concog.2020.102960

Appel, K., Pipa, G., \& Dresler, M. (2018). Investigating consciousness in the sleep laboratory - an interdisciplinary perspective on lucid dreaming. Interdisciplinary Science Reviews, 43(2), 192-207. https://doi.org/10.1080/03080188.2017.1380468

Aspy, D. J. (2020). Findings From the International Lucid Dream Induction Study. Frontiers in Psychology, 11. https://doi.org/10.3389/fpsyg.2020.01746

Aspy, D. J., Delfabbro, P., Proeve, M., \& Mohr, P. (2017). Reality testing and the mnemonic induction of lucid dreams: Findings from the national Australian lucid dream induction study. Dreaming, 27(3), 206-231. https://doi.org/10.1037/drm0000059

Aurora, R. N., Zak, R. S., Auerbach, S. H., Casey, K. R., Chowdhuri, S., Karippot, A., Maganti, R. K., Ramar, K., Kristo, D. A., Bista, S. R., Lamm, C. I., \& Morgenthaler, T. I. (2010). Best Practice Guide for the Treatment of Nightmare Disorder in Adults. Journal of Clinical Sleep Medicine, 06(04), 389-401.

Baird, B., Mota-Rolim, S. A., \& Dresler, M. (2019). The cognitive neuroscience of lucid dreaming. Neuroscience \& Biobehavioral Reviews, 100, 305-323. https://doi.org/10.1016/j.neubiorev.2019.03.008

Barrett, D. (1992). Just how lucid are lucid dreams? Dreaming, 2(4), 221-228. https://doi.org/10.1037/h0094362

Blagrove, M., Fouquet, N. C., Henley-Einion, J. A., Pace-Schott, E. F., Davies, A. C., Neuschaffer, J. L., \& Turnbull, O. H. (2011). Assessing the Dream-Lag Effect for REM and NREM Stage 2 Dreams. PLOS ONE, 6(10), e26708. https://doi.org/10.1371/journal.pone.0026708

Blanchette-Carrière, C., Julien, S.-H., Picard-Deland, C., Bouchard, M., Carrier, J., Paquette, T., \& Nielsen, T. (2020). Attempted induction of signalled lucid dreaming by transcranial alternating current stimulation. Consciousness and Cognition, 83, 102957. https://doi.org/10.1016/j.concog.2020.102957

Brooks, J. E., \& Vogelsong, J. A. (1999). The conscious exploration of dreaming: Discovering how we create and control our dreams. 1st Books Library.

Carr, M., Konkoly, K., Mallett, R., Edwards, C., Appel, K., \& Blagrove, M. (2020). Combining presleep cognitive training and REM-sleep stimulation in a laboratory morning nap for lucid dream induction. Psychology of Consciousness: Theory, Research, and Practice. Under revision. https://doi.org/10.1037/cns0000227

Christensen, R. H. B. (2019). ordinal: Regression Models for Ordinal Data (2019.12-10) [Computer software]. https://CRAN.R-project.org/package=ordinal 
de Macêdo, T. C. F., Ferreira, G. H., de Almondes, K. M., Kirov, R., \& Mota-Rolim, S. A. (2019). My Dream, My Rules: Can Lucid Dreaming Treat Nightmares? Frontiers in Psychology, 10. https://doi.org/10.3389/fpsyg.2019.02618

Dresler, M., Eibl, L., Fischer, C. F., Wehrle, R., Spoormaker, V. I., Steiger, A., Czisch, M., \& Pawlowski, M. (2014). Volitional components of consciousness vary across wakefulness, dreaming and lucid dreaming. Frontiers in Psychology, 4. https://doi.org/10.3389/fpsyg.2013.00987

Dresler, M., Koch, S. P., Wehrle, R., Spoormaker, V. I., Holsboer, F., Steiger, A., Sämann, P. G., Obrig, H., \& Czisch, M. (2011). Dreamed Movement Elicits Activation in the Sensorimotor Cortex. Current Biology, 21(21), 1833-1837. https://doi.org/10.1016/j.cub.2011.09.029

Dresler, M., Wehrle, R., Spoormaker, V. I., Koch, S. P., Holsboer, F., Steiger, A., Obrig, H., Sämann, P. G., \& Czisch, M. (2012). Neural Correlates of Dream Lucidity Obtained from Contrasting Lucid versus Non-Lucid REM Sleep: A Combined EEG/fMRI Case Study. Sleep, 35(7), 1017-1020. https://doi.org/10.5665/sleep.1974

Dyck, S., Kummer, N., König, N., Schredl, M., \& Kühnel, A. (2018). Effects of lucid dream induction on external-rated lucidity, dream emotions, and dream bizarreness. International Journal of Dream Research, 74-78. https://doi.org/10.11588/ijodr.2018.1.43867

Dyck, S., Schredl, M., \& Kühnel, A. (2017). Lucid dream induction using three different cognitive methods. International Journal of Dream Research, 10(2), 151-156. https://doi.org/10.11588/ijodr.2017.2.37498

Ellis, J. G., Koninck, J. D., \& Bastien, C. H. (2020). Managing Insomnia Using Lucid Dreaming Training: A Pilot Study. Behavioral Sleep Medicine, 0(0), 1-11. https://doi.org/10.1080/15402002.2020.1739688

Erlacher, D., \& Schredl, M. (2008). Do REM (lucid) dreamed and executed actions share the same neural substrate? International Journal of Dream Research, 714. https://doi.org/10.11588/ijodr.2008.1.20

Erlacher, D., \& Stumbrys, T. (2020). Wake Up, Work on Dreams, Back to Bed and Lucid Dream: A Sleep Laboratory Study. Frontiers in Psychology, 11. https://doi.org/10.3389/fpsyg.2020.01383

Fazekas, P., \& Nemeth, G. (2018). Dream experiences and the neural correlates of perceptual consciousness and cognitive access. Philosophical Transactions of the Royal Society B: Biological Sciences, 373(1755), 20170356. https://doi.org/10.1098/rstb.2017.0356

Fazekas, P., \& Overgaard, M. (2016). Multidimensional Models of Degrees and Levels of Consciousness. Trends in Cognitive Sciences, 20(10), 715-716. https://doi.org/10.1016/j.tics.2016.06.011

Fazekas, P., \& Overgaard, M. (2018). A Multi-Factor Account of Degrees of Awareness. Cognitive Science, 42(6), 1833-1859. https://doi.org/10.1111/cogs.12478

Fernández-Espejo, D., \& Owen, A. M. (2013). Detecting awareness after severe brain injury. Nature Reviews Neuroscience, 14(11), 801-809. https://doi.org/10.1038/nrn3608 
Fosse, M. J., Fosse, R., Hobson, J. A., \& Stickgold, R. J. (2003). Dreaming and Episodic Memory: A Functional Dissociation? Journal of Cognitive Neuroscience, 15(1), 1-9. https://doi.org/10.1162/089892903321107774

Gackenbach, J. (1988). The Psychological Content of Lucid versus Nonlucid Dreams. In J. Gackenbach \& S. LaBerge (Eds.), Conscious Mind, Sleeping Brain: Perspectives on Lucid Dreaming (pp. 181-220). Springer New York. https://doi.org/10.1007/978-1-4757-0423-5_9

Garfield, P., Fellows, P., Halliday, G., \& Malamud, J. R. (1988). Clinical Applications of Lucid Dreaming. In J. Gackenbach \& S. LaBerge (Eds.), Conscious Mind, Sleeping Brain: Perspectives on Lucid Dreaming (pp. 289-319). Springer New York. https://doi.org/10.1007/978-1-4757-0423-5_12

Garrett, L. (2017). Utilising dreambody choreutics to integrate somatics with lucid dream criteria. Body, Movement and Dance in Psychotherapy, 12(2), 145-158. https://doi.org/10.1080/17432979.2016.1231134

Gebremedhin, E. (1987). Problems at refining the "lucid" label: Shooting at a moving target. Lucidity Letter, 6(1), 80.

Gieselmann, A., Aoudia, M. A., Carr, M., Germain, A., Gorzka, R., Holzinger, B., Kleim, B., Krakow, B., Kunze, A. E., Lancee, J., Nadorff, M. R., Nielsen, T., Riemann, D., Sandahl, H., Schlarb, A. A., Schmid, C., Schredl, M., Spoormaker, V. I., Steil, R., ... Pietrowsky, R. (2019). Aetiology and treatment of nightmare disorder: State of the art and future perspectives. Journal of Sleep Research, 28(4), e12820. https://doi.org/10.1111/jsr.12820

Gillespie, G. (1984). Problems related to experimentation while dreaming lucidly. Lucidity Letter, 3(2/3). https://journals.macewan.ca/lucidity/article/view/629/543

Gott, J., Rak, M., Bovy, L., Peters, E., van Hooijdonk, C. F. M., Mangiaruga, A., Varatheeswaran, R., Chaabou, M., Gorman, L., Wilson, S., Weber, F., Talamini, L., Steiger, A., \& Dresler, M. (2020). Sleep fragmentation and lucid dreaming. Consciousness and Cognition, 84, 102988. https://doi.org/10.1016/j.concog.2020.102988

Green, C. (1968). Lucid Dreams (1st edition). Institute of Psychophysical Research. Hearne, K. M. (1978). Lucid dreams: An electro-physiological and psychological study [Ph.D.]. University of Liverpool.

Hobson, J. A. (2009). The Neurobiology of Consciousness: Lucid Dreaming Wakes Up. International Journal of Dream Research, 41-44. https://doi.org/10.11588/ijodr.2009.2.403

Hobson, J. A., Pace-Schott, E. F., \& Stickgold, R. (2000). Dreaming and the brain: Toward a cognitive neuroscience of conscious states. Behavioral and Brain Sciences, 23(6), 793-842. https://doi.org/10.1017/S0140525X00003976

Holzinger, B., Klösch, G., \& Saletu, B. (2015). Studies with lucid dreaming as add-on therapy to Gestalt therapy. Acta Neurologica Scandinavica, 131(6), 355-363. https://doi.org/10.1111/ane.12362

Holzinger, B., Saletu, B., \& Klösch, G. (2020). Cognitions in Sleep: Lucid Dreaming as an Intervention for Nightmares in Patients With Posttraumatic Stress Disorder. Frontiers in Psychology, 11. https://doi.org/10.3389/fpsyg.2020.01826 
Horton, C. L. (2020). Key Concepts in Dream Research: Cognition and Consciousness Are Inherently Linked, but Do No Not Control "Control"! Frontiers in Human Neuroscience, 14. https://doi.org/10.3389/fnhum.2020.00259

Hunt, H. T. (1986). Some Relations Between the Cognitive Psychology of Dreams and Dream Phenomenology. The Journal of Mind and Behavior, 7(2/3), 213-228.

Kahan, T. L. (1994). Measuring dream self-reflectiveness: A comparison of two approaches. Dreaming, 4(3), 177-193. https://doi.org/10.1037/h0094411

Kahan, T. L., \& LaBerge, S. P. (2011). Dreaming and waking: Similarities and differences revisited. Consciousness and Cognition, 20(3), 494-514. https://doi.org/10.1016/j.concog.2010.09.002

Kahan, T. L., \& Sullivan, K. T. (2012). Assessing metacognitive skills in waking and sleep: A psychometric analysis of the Metacognitive, Affective, Cognitive Experience (MACE) questionnaire. Consciousness and Cognition, 21(1), 340352. https://doi.org/10.1016/j.concog.2011.11.005

Kellog III, E. W. (1989). Mapping Territories: A Phenomenology of Lucid Dream Reality. Lucidity Letter, 8(2). https://journals.macewan.ca/lucidity/article/view/830/770

Konkoly, K., \& Burke, C. T. (2019). Can learning to lucid dream promote personal growth? Dreaming, 29(2), 113-126. https://doi.org/10.1037/drm0000101

Kühle, L. (2015). Insight: What Is It, Exactly? - A Commentary on Ursula Voss \& Allan Hobson. In T. K. Metzinger \& J. M. Windt (Eds.), Open MIND (pp. 1-13). MIND Group. https://doi.org/10.15502/9783958570696

LaBerge, S. (1980). Lucid Dreaming as a Learnable Skill: A Case Study. Perceptual and Motor Skills, 51(3_suppl2), 1039-1042. https://doi.org/10.2466/pms.1980.51.3f.1039

LaBerge, S. (1988). The Psychophysiology of Lucid Dreaming. In J. Gackenbach \& S. LaBerge (Eds.), Conscious Mind, Sleeping Brain: Perspectives on Lucid Dreaming (pp. 135-153). Springer New York. https://doi.org/10.1007/978-14757-0423-5_7

LaBerge, S., \& DeGracia, D. J. (2000). Varieties of lucid dreaming experience. In R. G. Kunzendorf \& B. Wallace (Eds.), Individual Differences in Conscious Experience (pp. 269-307). John Benjamins Publishing.

LaBerge, S., LaMarca, K., \& Baird, B. (2018). Pre-sleep treatment with galantamine stimulates lucid dreaming: A double-blind, placebo-controlled, crossover study. PLOS ONE, 13(8), e0201246. https://doi.org/10.1371/journal.pone.0201246

LaBerge, S., Nagel, L. E., Dement, W. C., \& Zarcone, V. P. (1981). Lucid Dreaming Verified by Volitional Communication during Rem Sleep. Perceptual and Motor Skills, 52(3), 727-732. https://doi.org/10.2466/pms.1981.52.3.727

LaBerge, S., Phillips, L., \& Levitan, L. (1994). An hour of wakefulness before morning naps makes lucidity more likely. NightLight, 6(3). http://www.lucidity.com/NL63.RU.Naps.html

Lee, M.-N. (2017). Reflective awareness and cognitive abilities in dreams: Implications for lucid dream research. International Journal of Dream Research, 157-163. https://doi.org/10.11588/ijodr.2017.2.40294

Lee, M.-N. (2018). A phenomenological study of reflective awareness in dreams: Characteristics of attention, memory, and anticipation. International Journal of Dream Research, 6-12. https://doi.org/10.11588/ijodr.2018.1.40338 
Lee, M.-N., \& Kuiken, D. (2015). Continuity of reflective awareness across waking and dreaming states. Dreaming, 25(2), 141-159. https://doi.org/10.1037/a0039147

Lemyre, A., Légaré-Bergeron, L., Landry, R. B., Garon, D., \& Vallières, A. (2020). HighLevel Control in Lucid Dreams. Imagination, Cognition and Personality, 0276236620909544. https://doi.org/10.1177/0276236620909544

Leslie, K., \& Ogilvie, R. (1996). Vestibular dreams: The effect of rocking on dream mentation. Dreaming, 6(1), 1-16. https://doi.org/10.1037/h0094442

Malinowski, J. E., \& Horton, C. L. (2014). Memory sources of dreams: The incorporation of autobiographical rather than episodic experiences. Journal of Sleep Research, 23(4), 441-447. https://doi.org/10.1111/jsr.12134

Mallett, R. (2020). Partial memory reinstatement while (lucid) dreaming to change the dream environment. Consciousness and Cognition, 83, 102974. https://doi.org/10.1016/j.concog.2020.102974

Moss, K. (1986). The dream lucidity continuum. Lucidity Letter, 5(2), 25-28.

Mota-Rolim, S. A., \& Araujo, J. F. (2013). Neurobiology and clinical implications of lucid dreaming. Medical Hypotheses, 81(5), 751-756. https://doi.org/10.1016/j.mehy.2013.04.049

Mota-Rolim, S. A., Erlacher, D., Tort, A. B. L., Araujo, J. F., \& Ribeiro, S. (2010). Different kinds of subjective experience during lucid dreaming may have different neural substrates: Commentary on "The neurobiology of consciousness: Lucid dreaming wakes up" by J. Allan Hobson. International Journal of Dream Research, 3(1), 33-35.

Mota-Rolim, S. A., Targino, Z. H., Souza, B. C., Blanco, W., Araujo, J. F., \& Ribeiro, S. (2013). Dream characteristics in a Brazilian sample: An online survey focusing on lucid dreaming. Frontiers in Human Neuroscience, 7. https://doi.org/10.3389/fnhum.2013.00836

Nielsen, T. A. (2004). Chronobiological features of dream production. Sleep Medicine Reviews, 8(5), 403-424. https://doi.org/10.1016/j.smrv.2004.06.005

Nielsen, T. A. (2017). Microdream neurophenomenology. Neuroscience of Consciousness, 2017(1). https://doi.org/10.1093/nc/nix001

Noreika, V., Windt, J. M., Lenggenhager, B., \& Karim, A. A. (2010). New perspectives for the study of lucid dreaming: From brain stimulation to philosophical theories of self-consciousness. International Journal of Dream Research, 36-45. https://doi.org/10.11588/ijodr.2010.1.586

Ogilvie, R. D., Hunt, H. T., Tyson, P. D., Lucescu, M. L., \& Jeakins, D. B. (1982). Lucid Dreaming and Alpha Activity: A Preliminary Report. Perceptual and Motor Skills, 55(3), 795-808. https://doi.org/10.2466/pms.1982.55.3.795

Payne, J. D. (2014). The (gamma) power to control our dreams. Nature Neuroscience, 17(6), 753-755. https://doi.org/10.1038/nn.3727

Price, R. F., \& Cohen, D. B. (1988). Lucid Dream Induction. In J. Gackenbach \& S. LaBerge (Eds.), Conscious Mind, Sleeping Brain: Perspectives on Lucid Dreaming (pp. 105-134). Springer New York. https://doi.org/10.1007/978-14757-0423-5_6

Purcell, S., Mullington, J., Moffitt, A., Hoffmann, R., \& Pigeau, R. (1986). Dream SelfReflectiveness as a Learned Cognitive Skill. Sleep, 9(3), 423-437. https://doi.org/10.1093/sleep/9.3.423 
Rechtschaffen, A. (1978). The single-mindedness and isolation of dreams. Sleep, 1(1), 97-109. https://doi.org/10.1093/sleep/1.1.97

Revonsuo, A., \& Valli, K. (2010). Dreaming as a model system for consciousness research. In E. K. Perry, D. Collerton, F. E. N. LeBeau, \& H. Ashton (Eds.), New Horizons in the Neuroscience of Consciousness. John Benjamins Publishing.

Ribeiro, N., Gounden, Y., \& Quaglino, V. (2020). Is There a Link Between Frequency of Dreams, Lucid Dreams, and Subjective Sleep Quality? Frontiers in Psychology, 11. https://doi.org/10.3389/fpsyg.2020.01290

Schädlich, M., \& Erlacher, D. (2012). Applications of lucid dreams: An online study. International Journal of Dream Research, 134-138. https://doi.org/10.11588/ijodr.2012.2.9505

Schädlich, M., Erlacher, D., \& Schredl, M. (2017). Improvement of darts performance following lucid dream practice depends on the number of distractions while rehearsing within the dream - a sleep laboratory pilot study. Journal of Sports Sciences, 35(23), 2365-2372. https://doi.org/10.1080/02640414.2016.1267387

Schadow, C., Schredl, M., Rieger, J., \& Göritz, A. S. (2018). The relationship between lucid dream frequency and sleep quality: Two cross-sectional studies. International Journal of Dream Research, 11(2), 154-159.

Schredl, M., Dyck, S., \& Kühnel, A. (2020). Lucid Dreaming and the Feeling of Being Refreshed in the Morning: A Diary Study. Clocks \& Sleep, 2(1), 54-60. https://doi.org/10.3390/clockssleep2010007

Schredl, M., \& Hofmann, F. (2003). Continuity between waking activities and dream activities. Consciousness and Cognition, 12(2), 298-308. https://doi.org/10.1016/S1053-8100(02)00072-7

Schredl, M., Rieger, J., \& Göritz, A. S. (2018). Measuring lucid dreaming skills: A new questionnaire (LUSK). International Journal of Dream Research, 11(1), 54-61. https://doi.org/10.11588/ijodr.2018.1.44040

Sikka, P., Pesonen, H., \& Revonsuo, A. (2018). Peace of mind and anxiety in the waking state are related to the affective content of dreams. Scientific Reports, 8(1), 12762. https://doi.org/10.1038/s41598-018-30721-1

Smallwood, J., \& Schooler, J. W. (2015). The Science of Mind Wandering: Empirically Navigating the Stream of Consciousness. Annual Review of Psychology, 66(1), 487-518. https://doi.org/10.1146/annurev-psych-010814-015331

Soffer-Dudek, N. (2020). Are Lucid Dreams Good for Us? Are We Asking the Right Question? A Call for Caution in Lucid Dream Research. Frontiers in Neuroscience, 13. https://doi.org/10.3389/fnins.2019.01423

Somers, R. H. (1962). A New Asymmetric Measure of Association for Ordinal Variables. American Sociological Review, 27(6), 799-811. JSTOR. https://doi.org/10.2307/2090408

Sparrow, G. S. (2019). Fading light and sluggish flight: A two-dimensional model of consciousness in lucid dreams. International Journal of Dream Research, 12(30), 82-88. https://doi.org/10.11588/ijodr.2019.1.57801

Sparrow, G. S., Carlson, R., \& Hurd, R. (2016). Assessing the Perceived Differences in Post-Galantamine Lucid Dreams vs. Non-Galantamine Lucid Dreams. International Journal of Dream Research, 71-74. https://doi.org/10.11588/ijodr.2016.1.25606 
Sparrow, G. S., Hurd, R., Carlson, R., \& Molina, A. (2018). Exploring the effects of galantamine paired with meditation and dream reliving on recalled dreams: Toward an integrated protocol for lucid dream induction and nightmare resolution. Consciousness and Cognition, 63, 74-88. https://doi.org/10.1016/j.concog.2018.05.012

Sparrow, G. S., Thurston, M., \& Carlson, R. (2013). Dream reliving and meditation as a way to enhance reflectiveness and constructive engagement in dreams. International Journal of Dream Research, 6(2), 84-93.

Spoormaker, V. I., \& Bout, J. van den. (2006). Lucid Dreaming Treatment for Nightmares: A Pilot Study. Psychotherapy and Psychosomatics, 75(6), 389-394. https://doi.org/10.1159/000095446

Spoormaker, V. I., Bout, J. van den, \& Meijer, E. J. G. (2003). Lucid Dreaming Treatment for Nightmares: A Series of Cases. Dreaming, 13(3), 181-186. https://doi.org/10.1023/A:1025325529560

Stewart, D. W., \& Koulack, D. (1989). A Rating System for Lucid Dream Content. Imagination, Cognition and Personality, 9(1), 67-74. https://doi.org/10.2190/NNP2-22V0-6K7H-A6J8

Stocks, A., Carr, M., Mallett, R., Konkoly, K., Hicks, A., Crawford, M., Schredl, M., \& Bradshaw, C. (2020). Dream lucidity is associated with positive waking mood. Consciousness and Cognition, 83, 102971. https://doi.org/10.1016/j.concog.2020.102971

Stoet, G. (2010). PsyToolkit: A software package for programming psychological experiments using Linux. Behavior Research Methods, 42(4), 1096-1104. https://doi.org/10.3758/BRM.42.4.1096

Stoet, G. (2017). PsyToolkit: A Novel Web-Based Method for Running Online Questionnaires and Reaction-Time Experiments. Teaching of Psychology, 44(1), 24-31. https://doi.org/10.1177/0098628316677643

Stumbrys, T., \& Erlacher, D. (2012). Lucid dreaming during NREM sleep: Two case reports. International Journal of Dream Research, 151-155. https://doi.org/10.11588/ijodr.2012.2.9483

Stumbrys, T., \& Erlacher, D. (2014). The Science of Lucid Dream Induction. In R. Hurd \& K. Bulkeley (Eds.), Lucid Dreaming: New Perspectives on Consciousness in Sleep (Vol. 1, pp. 77-102). Praeger.

Stumbrys, T., Erlacher, D., Johnson, M., \& Schredl, M. (2014). The Phenomenology of Lucid Dreaming: An Online Survey. The American Journal of Psychology, 127(2), 191-204. JSTOR.

Stumbrys, T., Erlacher, D., Schädlich, M., \& Schredl, M. (2012). Induction of lucid dreams: A systematic review of evidence. Consciousness and Cognition, 21(3), 1456-1475. https://doi.org/10.1016/j.concog.2012.07.003

Stumbrys, T., Erlacher, D., \& Schredl, M. (2013). Testing the involvement of the prefrontal cortex in lucid dreaming: A tDCS study. Consciousness and Cognition, 22(4), 1214-1222. https://doi.org/10.1016/j.concog.2013.08.005

Stumbrys, T., Erlacher, D., \& Schredl, M. (2016). Effectiveness of motor practice in lucid dreams: A comparison with physical and mental practice. Journal of Sports Sciences, 34(1), 27-34. https://doi.org/10.1080/02640414.2015.1030342 
Taitz, I. Y. (2014). Clinical Applications of Lucid Dreaming Therapy. In R. Hurd \& K. Bulkeley (Eds.), Lucid Dreaming: New Perspectives on Consciousness in Sleep (Vol. 1, pp. 167-192). Praeger.

Tart, C. (1985). What do we mean by lucidity? Lucidity Letter, 4(2), 12-17.

Tholey, P. (1983). Techniques for Inducing and Manipulating Lucid Dreams. Perceptual and Motor Skills, 57(1), 79-90. https://doi.org/10.2466/pms.1983.57.1.79

Vallat, R. (2018). Pingouin: Statistics in Python. Journal of Open Source Software, 3(31), 1026. https://doi.org/10.21105/joss.01026

Vallat, R., \& Ruby, P. M. (2019). Is It a Good Idea to Cultivate Lucid Dreaming? Frontiers in Psychology, 10. https://doi.org/10.3389/fpsyg.2019.02585

van Eeden, F. (1913). A study of dreams. Proceedings of the Society for Psychical Research, 26, 431-461.

van Rijn, E., Eichenlaub, J. B., Lewis, P. A., Walker, M. P., Gaskell, M. G., Malinowski, J. E., \& Blagrove, M. (2015). The dream-lag effect: Selective processing of personally significant events during Rapid Eye Movement sleep, but not during Slow Wave Sleep. Neurobiology of Learning and Memory, 122, 98-109. https://doi.org/10.1016/j.nlm.2015.01.009

Voss, U., D’Agostino, A., Kolibius, L., Klimke, A., Scarone, S., \& Hobson, J. A. (2018). Insight and Dissociation in Lucid Dreaming and Psychosis. Frontiers in Psychology, 9. https://doi.org/10.3389/fpsyg.2018.02164

Voss, U., Holzmann, R., Hobson, A., Paulus, W., Koppehele-Gossel, J., Klimke, A., \& Nitsche, M. A. (2014). Induction of self awareness in dreams through frontal low current stimulation of gamma activity. Nature Neuroscience, 17(6), 810-812. https://doi.org/10.1038/nn.3719

Voss, U., Holzmann, R., Tuin, I., \& Hobson, A. J. (2009). Lucid Dreaming: A State of Consciousness with Features of Both Waking and Non-Lucid Dreaming. Sleep, 32(9), 1191-1200. https://doi.org/10.1093/sleep/32.9.1191

Voss, U., Schermelleh-Engel, K., Windt, J., Frenzel, C., \& Hobson, A. (2013). Measuring consciousness in dreams: The lucidity and consciousness in dreams scale. Consciousness and Cognition, 22(1), 8-21. https://doi.org/10.1016/j.concog.2012.11.001

Watson, D., Clark, L. A., \& Tellegen, A. (1988). Development and validation of brief measures of positive and negative affect: The PANAS scales. Journal of Personality and Social Psychology, 54(6), 1063-1070. https://doi.org/10.1037/0022-3514.54.6.1063

Windt, J. M. (2010). The immersive spatiotemporal hallucination model of dreaming. Phenomenology and the Cognitive Sciences, 9(2), 295-316. https://doi.org/10.1007/s11097-010-9163-1

Windt, J. M., Nielsen, T., \& Thompson, E. (2016). Does Consciousness Disappear in Dreamless Sleep? Trends in Cognitive Sciences, 20(12), 871-882. https://doi.org/10.1016/j.tics.2016.09.006

Windt, J. M., \& Noreika, V. (2011). How to integrate dreaming into a general theory of consciousness-A critical review of existing positions and suggestions for future research. Consciousness and Cognition, 20(4), 1091-1107. https://doi.org/10.1016/j.concog.2010.09.010

Worsley, A. (1984). Lucid dream definition. Lucidity Letter, 3(2), 11-12. 
Worsley, A. (1988). Personal Experiences in Lucid Dreaming. In J. Gackenbach \& S. LaBerge (Eds.), Conscious Mind, Sleeping Brain: Perspectives on Lucid Dreaming (pp. 321-341). Springer New York. https://doi.org/10.1007/978-14757-0423-5 13

Yu, C., \& Shen, H. (2020). Bizarreness of Lucid and Non-lucid Dream: Effects of Metacognition. Frontiers in Psychology, 10. https://doi.org/10.3389/fpsyg.2019.02946

Zadra, A. L., \& Pihl, R. O. (1997). Lucid Dreaming as a Treatment for Recurrent Nightmares. Psychotherapy and Psychosomatics, 66(1), 50-55. https://doi.org/10.1159/000289106 